\title{
Graft Lesion Identification
}

National Cancer Institute

\section{Source}

National Cancer Institute. Graft Lesion Identification. NCI Thesaurus. Code C119567.

The identification of a non-neoplastic or neoplastic pathologic process taking place within a graft. 